\title{
DIAGNÓSTICO DA ARBORIZAÇÃO URBANA NO MUNICÍPIO DE TUPARENDI-RS
}

\author{
Natália Motter ${ }^{12}$ Nilvane G. Müller ${ }^{2}$.
}

\section{RESUMO}

A vegetação em vias públicas caracteriza-se como um dos mais importantes elementos que compõem o ecossistema das cidades e que, pelos benefícios que produz, deveria ser uma preocupação permanente de todo e qualquer planejamento urbano. O presente trabalho buscou caracterizar a arborização dos passeios das vias públicas asfaltadas de Tuparendi - RS, efetuando o levantamento quali-quantitativo das espécies arbóreas e arbustivas, avaliando suas condições fitossanitárias, bem como a adequação ao local de plantio. No inventário, foram verificadas 600 plantas, pertencentes a 25 famílias e 38 espécies, sendo 63,16 \% de exóticas. A espécie Nectandra membranacea (Canela) obteve o número mais expressivo de representantes, seguida por Murraya paniculata (Falsa murta), Mangifera indica (Mangueira), Lagerstroemia indica (Extremosa), Caesalpinia peltophoroides (Sibipiruna) e Ligustrum sp (Ligustro) que, juntas, representam 63,83\% da arborização da área analisada. De forma geral, a arborização urbana do município foi considerada como sadia, pois 96,17\% das árvores apresentavam boas condições fitossanitárias, com poucas árvores apresentando problemas de raiz e com a fiação elétrica.

Palavras-chave: Arborização viária; Fitossanidade; Planejamento urbano.

\section{DIAGNOSIS OF URBAN TREES IN THE MUNICIPALITY OF TUPARENDI-RS}

\section{ABSTRACT}

The vegetation on public roads is characterized as one of the most important components of the ecosystem of the cities and, for the benefits it produces, should be an ongoing concern of any urban planning. This study aimed to characterize the arborization of the paved roads of Tuparendi - RS, making the qualitative and quantitative survey of tree and shrub species, evaluating their phytosanitary conditions, as well as adapting to the planting site. In the inventory, there were verified 600 trees, belonging to 25 families and 38 species, being 63.16\% exotics. The species Nectandra membranous (Canela) had the most significant number of representatives, followed by Murraya paniculata (Falsa-murta), Mangifera indica (Mangueira), Lagerstroemia indica (Extremosa), Caesalpinia peltophoroides (Sibipiruna) and Ligustrum sp (Ligustro), which together represent $63.83 \%$ of the arborization of the municipal district. Overall, the arborization of the municipal district was considered healthy, because $96.17 \%$ of the trees presented good phytosanitary conditions, with only a few trees presenting problems with the roots and the electrical wiring.

Keywords: Street arborization; Phytosanitary condition; Urban planning.

\footnotetext{
${ }^{1}$ Bióloga, Acadêmica do curso de Especialização em Ciências Ambientais da Universidade Regional Integrada do Alto Uruguai e das Missões URI, campus de Santo Ângelo, RS. E-mail: nataliamotter@hotmail.com.

${ }^{2}$ Data recebimento: 11/09/2011 - Data de publicação: 15/12/2012

2. Bióloga, Prof.Dra Univ. Regional Integrada do Alto Uruguai e das Missões - URI, campus de Santo Ângelo, RS. E-mail: nil@urisan.tche.br.
} 


\section{INTRODUÇÃO}

Entende-se por arborização urbana o conjunto de terras públicas e privadas, com espécies predominantemente arbóreas que uma cidade apresenta, ou ainda, é um conjunto de vegetação arbórea natural ou cultivada que uma cidade apresenta em áreas particulares, praças, parques e vias públicas (SILVA JÚNIOR e MÔNICO, 1994).

Nesse sentido, de acordo com Dantas e Souza (2004), planejar a arborização é indispensável para o desenvolvimento urbano, visando evitar prejuízos para o meio ambiente. Além disso, a arborização é fator determinante da salubridade ambiental, por ter influência direta sobre o bem estar do homem, em virtude dos múltiplos benefícios que fornece ao meio, pois contribui à estabilização climática, embeleza, oferece abrigo e alimento à fauna, bem como proporciona sombra e lazer nas praças, parques, jardins, ruas e avenidas de nossas cidades.

Ainda nesta abordagem, Veras (1986) afirma que a arborização urbana caracteriza-se como um dos mais importantes elementos que compõem o ecossistema das cidades e que, pelos benefícios que produz, deveria ser uma preocupação permanente de todo e qualquer planejamento urbano. Desse modo, Moura (2009) ressalta que planejar a arborização é indispensável para o desenvolvimento urbano, sendo que grande parte dos prejuízos causados à qualidade de vida dos habitantes pode ser amenizada pelo planejamento urbano, ampliando - se qualiquantitativamente as áreas verdes e a arborização de ruas.

Nesse contexto, Schuch (2006) salienta que para a arborização urbana propiciar benefícios à população, exige um planejamento criterioso e um manejo adequado. Para tanto, torna-se necessário o conhecimento do patrimônio arbóreo, que pode ser obtido por meio de inventário, recurso que se constitui em uma ferramenta fundamental para a obtenção de informações precisas acerca da população arbórea.

No que se refere à avaliação da arborização de ruas, esta pode ser executada através da realização de inventários qualitativos e/ou quantitativos. Segundo Milano (1988), a realização do inventário quantitativo da arborização pública permite definir e mapear com precisão a população total de árvores de ruas para fins de inventário qualitativo, além da identificação da composição real da arborização, entre outros aspectos.

Por meio de um inventário é possível verificar os erros e acertos na arborização de uma cidade. A importância do inventário está no fato de que através dele pode-se conhecer o patrimônio arbóreo e identificar as necessidades de manejo. Um dos aspectos mais importantes do inventário é quando este é realizado de forma a fornecer uma contínua atualização das informações (TAKAHASHI, 1994).

Para que a presença da árvore na via pública não venha a trazer transtornos e problemas futuros, é necessário conhecer as suas características e seu comportamento. Sua escolha há de ser criteriosa, cobrindo o maior número possível de quesitos técnicos exigidos, principalmente se plantada em calçadas e passeios públicos, tendo-se plena ciência de que é impossível encontrar a árvore ideal para esse fim (DANTAS e SOUZA, 2004). 
Para Lima (1995), não há uma receita geral. Cada cidade tem clima próprio e tipo de solo diferente. É importante que a diversidade da espécie seja respeitada e que se dê preferência às árvores comuns da região. A regra número um de uma saudável política de arborização urbana é a diversificação das espécies, desde que sejam distribuídas nas ruas de uma forma estética e paisagística.

Considerando que a arborização urbana vem merecendo uma atenção cada vez maior em função dos benefícios e até mesmo dos problemas que se apresentam em função da presença da árvore no contexto da cidade, o presente trabalho teve como objetivo realizar um levantamento quali-quantitativo das espécies arbóreas e arbustivas utilizadas na arborização do município de Tuparendi, fornecendo subsídios para futuros programas de monitoramento e manejo.

\section{MATERIAIS E MÉTODOS}

O estudo foi desenvolvido no perímetro urbano do município de Tuparendi. Este se situa na região noroeste do Rio Grande do Sul, a 537 km da capital gaúcha, compreendendo uma área de $308 \mathrm{~km}^{2}$, com população de 8.557 habitantes (IBGE, 2010). Localiza-se a uma latitude $27^{\circ} 45^{\prime} 23^{\prime \prime}$ sul e a uma longitude $54^{\circ} 28^{\prime} 54^{\prime \prime}$ oeste, com clima subtropical úmido e temperatura média anual de $17^{\circ} \mathrm{C}$. A economia do município está centrada no binômio soja-trigo. Há também programas incentivados por cooperativas e poder público, que estimulam a produção de leite, suínos e hortigranjeiros (FAMURS, 2010). Com característica essencialmente agrícola, está inserido no bioma Mata Atlântica, na região fitoecológica da Floresta Estacional Decidual (RIO GRANDE DO SUL, 2010).

A metodologia empregada consistiu, basicamente, no levantamento de todos os indivíduos vegetais existentes nas calçadas de passeio das vias públicas asfaltadas do município, através da observação e registro fotográfico.
Para o estudo, foram consideradas tanto espécies nativas como exóticas, de porte arbustivo a arbóreo. Aquelas espécies localizadas em canteiros centrais e praças foram excluídas da pesquisa. A identificação das espécies, enquadradas nas condições mencionadas, com seus respectivos nomes científicos e famílias, ocorreu através da consulta bibliográfica baseada em Lorenzi et al. (1998, 2000, 2001, 2004), Backes e Irgang (2002, 2004), Longhi (1995) e Judd et al (2009).

Para descrever cada indivíduo de maneira qualitativa, foram observadas as seguintes características, conforme Faria e Monteiro (2007):

Quanto à fitossanidade: $B o a$ - árvore vigorosa e sadia, sem sinais aparentes de ataque de insetos, doenças ou injúrias mecânicas, pequena ou nenhuma necessidade de manutenção, forma ou arquitetura característica da espécie; Regular - médias condições de vigor e saúde, necessita de pequenos reparos ou poda, apresenta descaracterização da forma, apresenta sinais de ataque de insetos, doença ou problemas

DIAGNÓSTICO DA ARBORIZAÇÃO URBANA NO... 
fisiológicos; Ruim - avançado e irreversível declínio, apresenta ataque muito severo por insetos, doença, presença de fungos (orelhas de pau) ou injúria mecânica, descaracterizando sua arquitetura ou desequilibrando o vegetal, problemas fisiológicos cujos reparos não resultarão em benefício para o indivíduo; Morte iminente - árvore seca ou com morte iminente.

Quanto ao desenvolvimento da raiz: Sem interferência - quando as raízes não estão expostas; Baixa interferência - quando a árvore apresenta alguma raiz exposta na calçada, porém não chega causar nem um tipo de prejuízo; Média interferência quando a árvore apresenta várias raízes expostas na calçada, podendo causar algum tipo de prejuízo; Alta Interferência - quando a árvore apresenta várias raízes expostas na calçada, já tendo causado algum tipo de prejuízo.

Quanto ao desenvolvimento da copa da árvore em relação à fiação: Sem interferência - quando o equipamento urbano ou edificação não está em contato com alguma parte da árvore; Ramal - quando a espécie, pelo seu crescimento normal, vai entrar em contato com algum equipamento; Telefone - quando a espécie, pelo seu crescimento normal, entra em contato com algum equipamento, não causando prejuízo imediato; Secundária - quando a espécie, pelo seu crescimento normal, pode entrar em contato com algum equipamento, estando em alto risco; Primária - quando a espécie, pelo seu crescimento normal, pode entrar em contato com algum equipamento, estando em alto risco, podendo causar prejuízo imediato.

O diagnóstico foi realizado com o uso de uma planilha de levantamento de dados, onde foram anotadas as informações referentes às ruas, aos passeios e aos indivíduos vegetais existentes. As visitas para coleta de dados ocorreram durante o mês de novembro e dezembro de 2010. Com base nos dados levantados, foi calculada a porcentagem de cada espécie ocorrente na área de estudo através do programa Microsoft Office Excel 2007 para Windows XP.

\section{RESULTADOS E DISCUSSÃO}

Nas quatro ruas percorridas no município de Tuparendi, foram inventariadas 600 plantas arbustivo-arbóreas, pertencentes a 25 famílias e 38 espécies, conforme a tabela 01. As famílias que apresentaram mais espécies foram: Fabaceae, Myrtaceae, Bignoniaceae e Rutaceae, com três espécies cada. As três primeiras famílias também foram as com maior representatividade de espécies no diagnóstico realizado por Stranghetti (2010) no município de Uchôa-SP e Lindenmaier (2008) em Cachoeira do Sul -RS.

Na composição da arborização, a espécie Nectandra membranacea obteve o número mais expressivo de representantes (92), correspondendo a 15,33\% do total de indivíduos. Destacam-se ainda as espécies Murraya paniculata (12,33\%), Mangifera indica (10,67\%), Lagerstroemia indica (9,17\%), Caesalpinia peltophoroides (9,17\%) e Ligustrum sp 
(7,17\%) que, juntas, perfazem 63,83\% da área estudada. De acordo com o Instituto Hórus (2005), o ligustro apresenta potencial invasivo, de modo que se dispersa com facilidade por sementes que caem, por aves e por rebrota, limitando a presença de outras espécies, demonstrando, dessa maneira, a perda de biodiversidade por invasão biológica.

Os dados obtidos mostraram-se favoráveis à afirmação de Milano e Dalcin (2000) de que cada espécie deve permanecer em torno de 10 a $15 \%$ do total de indivíduos da população arbórea de um município. Por outro lado, um grande número de espécies identificadas na área amostrada são pouco frequentes, comprometendo a diversidade vegetal da área urbana do município.

Numa perspectiva muito ampla e genérica da arborização de cidades brasileiras, observa-se certa uniformidade quanto ao emprego de algumas espécies, considerada normal pelo fato de uma cidade, geralmente, tentar imitar a arborização de outra. Vem daí a pouca diversidade, concentrando-se a maioria em um número reduzido de espécies, sempre acompanhadas dos mesmos problemas (SOUZA, 1994).

Na determinação das espécies, verificou-se que a arborização é composta por 36,84\% de árvores nativas e 63,16 \% de exóticas. Dentre estas se destacou, apresentando maior freqüência, a espécie Murraya paniculata, com 74 exemplares, correspondendo a 12,33\% da arborização da cidade.

Resultado semelhante foi encontrado em levantamento realizado por Coletto et al (2008) em Sete de Setembro - RS, onde Murraya paniculata detinha $12 \%$ da arborização.
Mondin (2006) chama a atenção para o enorme contingente de espécies exóticas utilizadas em jardins, praças e outras áreas públicas. Para o autor, é premente a necessidade das instituições governamentais desenvolverem mais pesquisas na área de plantas ornamentais, frutíferas e florestais nativas, tornando-as disponíveis para o mercado consumidor, a fim de que existam alternativas ao uso generalizado de espécies exóticas.

Das 38 espécies amostradas na pesquisa, 12 são frutíferas econômicas, representando juntas, 19,33\% da composição arbórea da área estudada, muito provavelmente plantadas pelos próprios moradores. A espécie que possui maior número de indivíduos é a Mangifera indica, num total de 64, demonstrando ações não planejadas, feitas de forma espontânea pela população, com a finalidade de alimentação humana. Para Costa et al. (1996), as árvores frutíferas econômicas não são indicadas para o plantio em vias públicas, pois comumente são susceptíveis a pragas, doenças e poluição. Além disso, Santos e Teixeira (2001) salientam que a frutificação das espécies poderá representar um efeito ornamental e servir de atrativo para a fauna local, mas desaconselham as espécies que produzam frutos grandes como a mangueira, pois esses frutos podem cair e causar danos a veículos, pedestres ou outro.

Corroborando com as idéias dos autores acima citados, Guizzo e Jasper (2005) afirmam que as espécies com frutos grandes, além de causar sérios danos aos pedestres, podem danificar carros e outros objetos, se houver queda de frutos na via pública. Nesses casos, a responsabilidade passa a ser do poder público por qualquer dano causado. E ainda, ao utilizar espécies que produzam frutos grandes

DIAGNÓSTICO DA ARBORIZAÇÃO URBANA NO.. 
normalmente consumidos pelas pessoas, poderá estar sendo estimulada a depredação estrutural da planta. Deve-se, então, priorizar a escolha de espécies nativas locais. Pela análise da vegetação do município, percebe-se a presença de espécies arbustivas distribuídas ao longo das vias públicas. Essas plantas constituem elementos de fundamental importância na organização de espaços, sendo essencialmente utilizadas como barreiras vegetais (LIRA FILHO, 2002). Além disso, os espécimes que se destacam isoladamente podem servir de referencial na paisagem para orientação do público. Por outro lado, os arbustos devem ter seu uso muito criterioso na arborização urbana, principalmente em função do porte baixo e das ramificações que comprometem a travessia dos transeuntes, oferecendo inúmeros problemas relacionados à visibilidade para o trânsito e sinalização (SANTOS e TEIXEIRA, 2001).

Em geral, as árvores analisadas do município, com referência à fitossanidade, se apresentaram em boas condições, sadias e com vigor (96,17\%), num total de 577 indivíduos. Somente $1,67 \%$ necessitava de pequenos reparos por apresentar sinais de ataque de insetos, doença ou problemas fisiológicos. Em estado ruim, com irreversível declínio, verificou-se 13 indivíduos e não houve ocorrências de árvores mortas. Esta situação é superior à encontrada por Coletto et al (2008) em Sete de Setembro - RS, onde 86,4\% das árvores foram classificadas como boas. Stranghetti e Silva (2010), na cidade de Uchôa - SP, também verificaram que $96 \%$ dos indivíduos amostrados não apresentaram sinais aparentes de algum tipo de injúria, podendo-se considerar que, em termos de qualidade das árvores, os municípios de Tuparendi e Uchôa são bem manejados.
Outro aspecto de análise importante para uma arborização de boa qualidade é a situação do sistema radicular, pois raízes excessivamente superficiais podem causar danos ao patrimônio público e contribuir para a ocorrência de acidentes. Em poucos casos, foram verificados problemas de raiz nas ruas. Para 74\% dos indivíduos, as raízes não estão expostas, predominando no município calçadas sem danos. Apenas 8\% das raízes têm alta interferência, já tendo causado prejuízos às calçadas. O Ficus benjamina foi a espécie que mais apresentou problemas, pois quando plantada em área reduzida, gera trincas e compromete a pavimentação, em decorrência da pressão exercida pelas raízes secundárias que são mais desenvolvidas que a raiz pivotante e dispõe-se em feixes paralelos ao solo.

Com relação ao contato da copa das árvores na rede elétrica, 476 indivíduos não apresentaram problemas com fiação, 3,50\% dos indivíduos amostrados apresentaram interferência das copas em ramal, 7,33\% em ramal de telefone, 2\% com interferência na rede primária e 7,83\% das espécies possuem interferência na rede secundária. As espécies Caesalpinia peltophoroides, Ficus benjamina e Mangifera indica, foram consideradas inadequadas para o local de plantio, já que apresentaram incompatibilidade com a rede de energia.

Para reduzir a ocorrência desses danos, devem ser selecionadas árvores com portes diferenciados, compatíveis com fiações e interferências subterrâneas, sendo eliminadas aquelas que se caracterizam por apresentarem a madeira mole, caule e ramos quebradiços, pois são vulneráveis a chuvas e ventos fortes, colocando em risco a segurança de pedestres, veículos e edificações. As árvores com

Natália Motter e Nilvane G. Müller REVSBAU, Piracicaba - SP, v.7, n.4, p.27-36, 2012 
raízes superficiais também devem ter o plantio limitado a locais onde suas raízes não danifiquem o pavimento (FRANCO, 1993).

Conforme Lorenzi (2003), nas calçadas de ruas sob fiação elétrica apenas espécies com menos de $8 \mathrm{~m}$ de altura, quando adultas, podem ser implantadas. Da mesma forma, em calçadas de ruas estreitas, somente espécies de copa estreita e alta ou piramidal devem ser implantadas para evitar a obstrução das vias pelo crescimento excessivo dos ramos laterais.

Tabela 1. Relação das espécies, famílias, origem e número de indivíduos dos exemplares vegetais encontrados na arborização das vias públicas do município de Tuparendi, RS.

\begin{tabular}{|c|c|c|c|c|}
\hline Nome Popular & Nome Científico & Família & Origem & $\begin{array}{c}\text { № de } \\
\text { Indivíduos }\end{array}$ \\
\hline Canela & Nectandra membranacea & Lauraceae & Nativa & 92 \\
\hline Falsa-murta & Murraya paniculata & Rutaceae & Exótica & 74 \\
\hline Mangueira & Mangifera indica & Anacardiaceae & Exótica & 64 \\
\hline Extremosa & Lagerstroemia indica & Lythraceae & Exótica & 55 \\
\hline Sibipiruna & Caesalpinia peltophoroides & Fabaceae & Nativa & 55 \\
\hline Ligustro & Ligustrum $s p$ & Oleaceae & Exótica & 43 \\
\hline Fícus & Ficus benjamina & Moraceae & Exótica & 33 \\
\hline Grevilha & Grevillea robusta & Proteaceae & Exótica & 25 \\
\hline Cipreste & Chamaecyparis sp & Cupressaceae & Exótica & 24 \\
\hline Palmeira & Archontophoenix alexandrae & Palmae & Exótica & 23 \\
\hline $\begin{array}{l}\text { Figueira-de- } \\
\text { jardim }\end{array}$ & Ficus auriculata & Moraceae & Exótica & 17 \\
\hline Pereira & Pyrus communis & Rosaceae & Exótica & 17 \\
\hline Nêspera & Eriobotrya japonica & Rosaceae & Exótica & 8 \\
\hline Pingo-de-ouro & Duranta repens & Verbenaceae & Exótica & 7 \\
\hline Cerejeira & Eugenia involucrata & Myrtaceae & Nativa & 6 \\
\hline Azaléia & Rhododendron simsii & Ericaceae & Exótica & 5 \\
\hline Cedro & Cedrela fissilis & Meliaceae & Nativa & 5 \\
\hline Bergamoteira & Citrus reticulata & Rutaceae & Exótica & 4 \\
\hline Espatódea & Spathodea nilotica & Bignoniaceae & Exótica & 4 \\
\hline Goiabeira & Psidium guajava & Myrtaceae & Exótica & 4 \\
\hline Hibisco & Hibiscus rosa-sinensis & Malvaceae & Exótica & 4 \\
\hline Pitangueira & Eugenia uniflora & Myrtaceae & Nativa & 4 \\
\hline Uva-do-Japão & Hovenia dulcis & Rhamnaceae & Exótica & 4 \\
\hline Cinamomo & Melia azedarach & Meliaceae & Exótica & 3 \\
\hline $\begin{array}{l}\text { Jacarandá- } \\
\text { mimoso }\end{array}$ & Jacaranda mimosaefolia & Bignoniaceae & Exótica & 2 \\
\hline Primavera & Brunfelsia uniflora & Solanaceae & Nativa & 2 \\
\hline Mamona & Ricinus communis & Euphorbiaceae & Exótica & 2 \\
\hline Ipê & Tabebuia chrysotricha & Bignoniaceae & Nativa & 2 \\
\hline Ingá & Inga vera & Fabaceae & Nativa & 2 \\
\hline Ixora & Ixora coccinea & Rubiaceae & Exótica & 2 \\
\hline Angico & Parapiptadenia rigida & Fabaceae & Nativa & 1 \\
\hline Butiazeiro & Butia eriospata & Palmae & Nativa & 1 \\
\hline Caquizeiro & Diospyros kaki & Ebenaceae & Exótica & 1 \\
\hline Erva-mate & Ilex paraguariensis & Aquifoliaceae & Nativa & 1 \\
\hline Guapuruvu & Schizolobium parahyba & Fabaceae & Nativa & 1 \\
\hline
\end{tabular}

DIAGNÓSTICO DA ARBORIZAÇÃO URBANA NO... 


\begin{tabular}{|c|c|c|c|c|}
\hline Limoeiro & Citrus limon & Rutaceae & Exótica & 1 \\
\hline Pau-ferro & Caesalpinia ferrea & Fabaceae & Nativa & 1 \\
\hline Tarumã & Vitex megapotamica & Verbenaceae & Nativa & 1 \\
\hline
\end{tabular}

\section{CONCLUSÕES}

No levantamento da arborização urbana do município de Tuparendi, percebeu-se que a população está compreendendo a importância de um ambiente ecologicamente equilibrado e que está buscando uma aproximação maior com a natureza, haja vista a grande quantidade de árvores encontrada. Em contrapartida, constatou-se uma acentuada irregularidade na distribuição das espécies, privilegiando-se espécies exóticas e frutíferas, principalmente da espécie Murraya paniculata e Mangifera indica, devendo ter seus plantios evitados por já terem atingido um percentual elevado nas vias públicas. Além disso, a utilização das espécies arbustivas deve ser reduzida, já que oferecem benefícios muito menores que as arbóreas na arborização urbana viária.

Em relação à fitossanidade, a maior parte dos indivíduos estudados encontrava-se em boas condições e não necessitava de podas. Em poucos casos, foram verificados problemas de raiz e com a fiação.

Por fim, cabe ressaltar que cada município possui sua realidade cultural, climática e pedológica, de forma que estes aspectos devem ser sempre considerados em primeiro plano antes do processo de seleção das espécies melhor indicadas para cada situação.

\section{REFERÊNCIAS BIBLIOGRÁFICAS}

BACKES, P.; IRGANG, B. Árvores do Sul - guia de identificação \& interesse ecológico. [S.l.]: Instituto Souza Cruz, 2002. 326 p.

BACKES, P.; IRGANG, B. Árvores cultivadas no sul do Brasil - guia de identificação e interesse paisagístico das principais espécies exóticas. Porto Alegre: Paisagem do Sul, 2004. 204 p.

COLETTO, E.P.; MÜLLER, N.G.; WOLSKI, S.S. Diagnóstico da arborização das vias públicas do Município de Sete de Setembro - RS. Revista da Sociedade Brasileira de Arborização Urbana, v.3, n. 2, p.110-122, 2008.

COSTA, L. M. S. A.; FILHO, L.E.M.; FARAH, I.M.C.; CAMISÃO, C. Arborização das ruas do bairro de Copacabana. In: 3. Congresso Brasileiro sobre Arborização Urbana, Bahia. Anais. Bahia: SBAU, 1996. p.79-88.

DANTAS, I. C.; SOUZA, C.M. C. Arborização urbana na cidade de Campina Grande-PB: Inventário e suas espécies. Revista de Biologia e Ciências da Terra. v.4, n.2, 2004.

FAMURS. Municípios. Disponível em: < http://www.famurs.com.br/\#>. Acesso em 05 dez. 2010. 
FARIA, J. L. G.; MONTEIRO, E. A. Arborização de Vias Públicas do Município de Jacareí - SP. Revista da Sociedade Brasileira de Arborização Urbana, Piracicaba, v.2, n.4, p. 20-33, 2007. Disponível em: < http://www.revsbau.esalq.usp.br/artigos_cientificos/artigo29.pdf>. Acesso em 05 dez. 2010.

FRANCO, C. C. D. de M. Programa um Milhão de Árvores - SVMA. In: Questão Ambiental Urbana: Cidade de São Paulo / Prefeitura Municipal de São Paulo, Secretaria Municipal do Verde e do Meio Ambiente. São Paulo: A Secretaria, 1993.

GUIZZO, D. J.; JASPER, A. Levantamento das espécies arbóreas dos passeios das vias públicas do Bairro Americano de Lajeado - RS, com indicação de problemas já existentes. PESQUISAS, BOTÂNICA, $\mathrm{N}^{\circ}$ 56:185208, São Leopoldo, 2005.

INSTITUTO BRASILEIRO DE GEOGRAFIA E $\quad$ ESTATÍSTICA. Cidades. Disponível em:<http://www.ibge.com.br/cidadesat/default.php>. Acesso em: 07 set. 2010.

INSTITUTO HÓRUS DE DESENVOLVIMENTO E CONSERVAÇÃO AMBIENTAL /THE NATURE CONSERVANCY. Ligustrum japonicum. $2005 . \quad$ Disponível em: <http://www.institutohorus.org.br/index.php?modulo=inf_ficha_ligustrum_japonicum>. Acesso em: 31 maio 2012.

JUDD, W. S; et al. Sistemática Vegetal : Um Enfoque Filogenético. 3 ed. Porto Alegre: Artmed, 2009.

LIMA, A. M. L. P. Árvores de Rua. Revista Globo Ciência, São Paulo, No 44, Março de 1995.

LINDENMAIER, D. de S.; SANTOS, N. O. Arborização urbana das praças de Cachoeira do Sul - RS - Brasil: Fitogeografia, diversidade e índices de áreas verdes. PESQUISAS, BOTÂNICA N 59: 307-320 São Leopoldo: Instituto Anchietano de Pesquisas, 2008.

LIRA FILHO, J. A. Paisagismo: elementos de composição e estética. Viçosa-MG: Aprenda Fácil, 2002. 194 p. 9. Coleção jardinagem e paisagismo. Série planejamento paisagísticos; v. 2.

LONGHI, R. A. Livro das Árvores: árvores e arvoretas do sul. Porto Alegre: L\&PM,1995.

LORENZI, H. Árvores brasileiras: manual de identificação e cultivo de plantas arbóreas nativas do Brasil. v. 2.2. ed. Nova Odessa: Instituto Plantarum, 1998.

Árvores brasileiras: manual de identificação e cultivo de plantas arbóreas nativas do Brasil. 3. ed. Nova Odessa: Instituto Plantarum, 2000.

Plantas ornamentais no Brasil: arbustivas, herbáceas e trepadeiras. 3. ed. Nova Odessa: Instituto Plantarum, 2001.

LORENZI, H.; SOUZA, H.M.; TORRES, M.A.V.; BACHER, L.B. Árvores Exóticas no Brasil: madeiras, ornamentais e aromáticas. 1.ed. Nova Odessa: Platarum, 2003. 352p.

LORENZI, H. et al. Árvores exóticas no Brasil: madeiras, ornamentais e aromáticas. Nova Odessa: Instituto Plantarum, 2004.

MILANO, M. S. Avaliação quali-quantitativa e manejo da arborização urbana: exemplo de Maringá - PR. Curitiba: UFPR, 1988. Tese (Doutorado em Ciências Florestais), Setor de Ciências Agrárias, Universidade Federal do Paraná, 1988.

MILANO, M.S.; DALCIN, E. Arborização de vias públicas. Rio de Janeiro: Light, 2000. 206p.

MONDIN, C. A. 2006. Espécies vegetais exóticas invasoras em florestas no Rio Grande do Sul. Anais do $57^{\circ}$ Congresso Nacional de Botânica, Porto Alegre, Brasil, p.529-531.

MOURA, T. de A.; SANTOS, V. L. L. V. Levantamento quali-quantitativo de espécies arbóreas e arbustivas na arborização viária urbana dos Bairros Centro e Centro Norte, Várzea Grande, Mato Grosso, Brasil. Revista da Sociedade Brasileira de Arborização Urbana, Piracicaba - SP, v.1, n.1, p.97-117, 2009. Disponível em: <http://www.revsbau.esalq.usp.br/artigos_cientificos/artigo74-versao_publicacao.pdf>. Acesso em: 07 set. 2010.

DIAGNÓSTICO DA ARBORIZAÇÃO URBANA NO... 
RIO GRANDE DO SUL. Projeto RS BIODIVERSIDADE. Disponível em: <http://www.biodiversidade.rs.gov.br> Acesso em: 05 dez. 2010.

SANTOS, N. R. Z. dos; TEIXEIRA, I. F. Arborização de vias públicas: ambiente x vegetação. Santa Cruz do Sul: Instituto Souza Cruz, 2001. 135p.

SCHUCH, M. I. S. Arborização Urbana: Uma contribuição à qualidade de vida com uso de geotecnologias. Dissertação (Mestrado em Geomática), Universidade Federal de Santa Maria, 2006.

SILVA JÚNIOR, O. A. B.; MÔNICO, M. O. M. Arborização em Harmonia com a Infraestrutura Urbana. In $1^{\mathrm{a}}$ Semana de Meio Ambiente. Prefeitura Municipal de Guarulhos: Secretaria de Meio Ambiente, 1994.

SOUZA, H. M. Algumas espécies nativas para arborização de vias públicas. In: CONGRESSO BRASILEIRO DE ARBORIZAÇÃO URBANA, 2, ENCONTRO NACIONAL SOBRE ARBORIZAÇÃO URBANA, 5, São Luiz. Anais. São Luiz: SBAU, 1994. p.67-74.

STRANGUETII, V.; SILVA, Z. A. V. Diagnóstico as Arborização das Vias Públicas do município de Uchôa-Sp. Revista da Sociedade Brasileira de Arborização Urbana, Piracicaba - SP, v.5, n2, p.124-138, 2010. Disponível em: <http://www.revsbau.esalq.usp.br/artigos_cientificos/artigo128-publicacao.pdf>. Acesso em: 05 dez. 2010.

TAKAHASHI, L. Y. Arborização urbana: inventário. In: CONGRESSO BRASILEIRO DE ARBORIZAÇÃO URBANA, 2., 1994, São Luís. Anais... São Luís: Sociedade Brasileira de Arborização Urbana, 1994. p.193-200.

VERAS, L. M. S. C. Plano de arborização de cidades - metodologia. In: CONGRESSO NORDESTINO DE ECOLOGIA. Recife - PE. Anais. Recife: UFRPE, Departamento de Biologia, 1986. p. 8-14. 